RESEARCH PAPER RP1270

Part of Journal of Research of the National Bureau of Standards, Volume 24, January 1940

\title{
SENSITIVE ANEROID DIAPHRAGM CAPSULE WITH NO DEFLECTION ABOVE A SELECTED PRESSURE
}

\author{
By W. G. Brombacher, V. H. Goerke, and F. Cordero
}

\section{ABSTRACT}

A sensitive diaphragm capsule has been designed in which the two corrugated diaphragms nest into each other at external air pressures above a desired value. Evacuated capsules of this type have particular application in measuring pressure with radio sondes of the Diamond-Hinman-Dunmore type, where the deflection of the contact arm is fixed. At the ground level the diaphragms are designed to nest into each other and deflection does not begin until the air pressure is reduced to the value called the cut-off pressure. Several elements of two capsules each were constructed with a cut-off pressure of 140 millibars. When installed in a radio sonde in place of the usual type, which is responsive over the entire range of pressures, a sevenfold increase in sensitivity in pressure measurement was obtained at altitudes above 46,000 feet.

In measuring air pressure with radio sondes of the DiamondHinman-Dunmore type, ${ }^{1}$ where the motion of the pressure contactor is a fixed distance, it is desirable, in some cases, to increase the sensitivity at high altitudes. To secure this increase in sensitivity, a disphragm capsule has been designed at the National Bureau of Standards, the two diaphragms of which, when evacuated and sealed off in accordance with the usual practice for capsules used to measure atmospheric pressure, nest into each other at air pressures greater than a selected value. At pressures less than this cut-off value, the capsule deflects normally. The nesting of the diaphragms prevents damage to the relatively sensitive diaphragms, which might be caused by excessive differential pressures. The new diaphragm element is designed so that the contact arm of the radio sonde deflects over the same distance for the pressure interval from the cut-off to zero pressures, as does the ordinary element from sea level to zero pressures.

The capsule, at zero pressure, is shown diagrammatically in figure 1. The connections needed for evacuating the capsule and for attachment to the radio sonde are not shown in figure 1 . It is apparent from the form of the capsule that, as the air is evacuated from its interior, it will gradually collapse and finally, at a definite differential pressure, the two diaphragms will nest into each other and remain nested for larger external pressures. The evacuated capsule starts deflecting when the air pressure is reduced to a pressure equal to the differential pressure at which nesting took place during evacuation. This is known as the cut-off pressure.

A pressure element of this type, consisting of two diaphragm capsules installed in a Diamond-Hinman-Dunmore radio sonde made by

\footnotetext{
1 Harry Diamond, Wilbur S. Hinman. Jr., and Francis W. Dunmore, $A$ method for the investigation of upper. air phenomena and its application to radio meteorography, J. Research NBS 20, 369 (1938) RP1082.
} 
Friez, is shown in figure 2. Two such elements were constructed. The diaphragms are 0.003 inch thick and 2.5 inches in diameter. They were formed hydraulically from soft beryllium copper, which was later hardened by heat treatment. Separate dies were used to form the upper and lower diaphragms. The complete pressure elements have a deflection of about 0.22 inch at the center for the pressure range from 140 to 0 millibars (105 to $0 \mathrm{~mm}$ of mercury). At greater air pressures, the diaphragms of each capsule nest into each other. As installed in the radio sonde, the first contact is made at about 140 millibars ( $105 \mathrm{~mm}$ of mercury), equivalent to an altitude of about 46,000 feet. Since the pressure element ordinarily installed in the radio sonde deflects over the range of contacts in the pressure range from 0 to 1,040 millibars, the gain in sensitivity on a pressure basis is about $7 \frac{1}{2}$ to 1 . The effect of temperature change $\left(0^{\circ}\right.$ to $+30^{\circ}$ C) on the deflections was found to be somewhat less than that to be expected on the basis of the temperature coefficient of the modulus of elasticity of beryllium copper.

In cooperation with H. Diamond and W. S. Hinman, one of the radio sondes was sent up attached to six sounding balloons, which reached an altitude of 85,500 feet. Seventy of the eighty contacts of the range operated during the flight. A temperature record was also secured. The minimum pressure obtained was 24 millibars (18

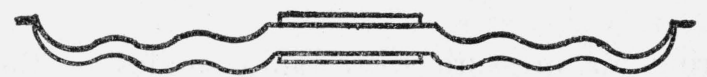

FrgURE 1.-Capsule in which the diaphragms nest into each other as the internal pressure is decreased or the external pressure increased.

$\mathrm{mm}$ of mercury). The action was satisfactory in all respects, including smooth motion of the contactor over the contacts.

Other designs may be indicated, using the formulas developed by W. A. Wildhack and V. H. Goerke. ${ }^{2}$ Thus two beryllium-copper capsules similar to those described above, and with the same shape of corrugations but of material 0.0045 inch thick, would have the same deflection in the pressure range 0 to 256 millibars ( 0 to 200 millimeters of mercury).

The effect of friction at the sliding contact should be considered. If the friction at the point of contact and the deflection range of the contact arm remain constant, while the stiffness of the pressure element and the multiplication of the mechanism are varied, the differential pressure necessary to balance the friction varies directly as the stiffness and inversely as the square of the diameter of the diaphragm capsule.

If data are required at air pressures above the cut-off point of the elements described, the usual type of pressure element can also be used, but should be arranged so as to record only in this pressure range. The sensitive element contactor would be so arranged that it would traverse the $\mathrm{s}_{\mathrm{S}}^{\mathrm{s}} \mathrm{sme}_{\mathrm{i}}$ contacts at pressures below its cut-off pressure.

This diaphragm capsule was developed at the National Bureau of Standards as a part of the program of upper-air investigations undertaken in cooperation with the National Geographic Society.

Washington, November 27, 1939.

${ }^{2}$ Corrugated Metal Diaphragms for Aircraft Pressure Measuring Instruments. Nat. Adv. Comm. Aero. Technical Note 738 (1939). 


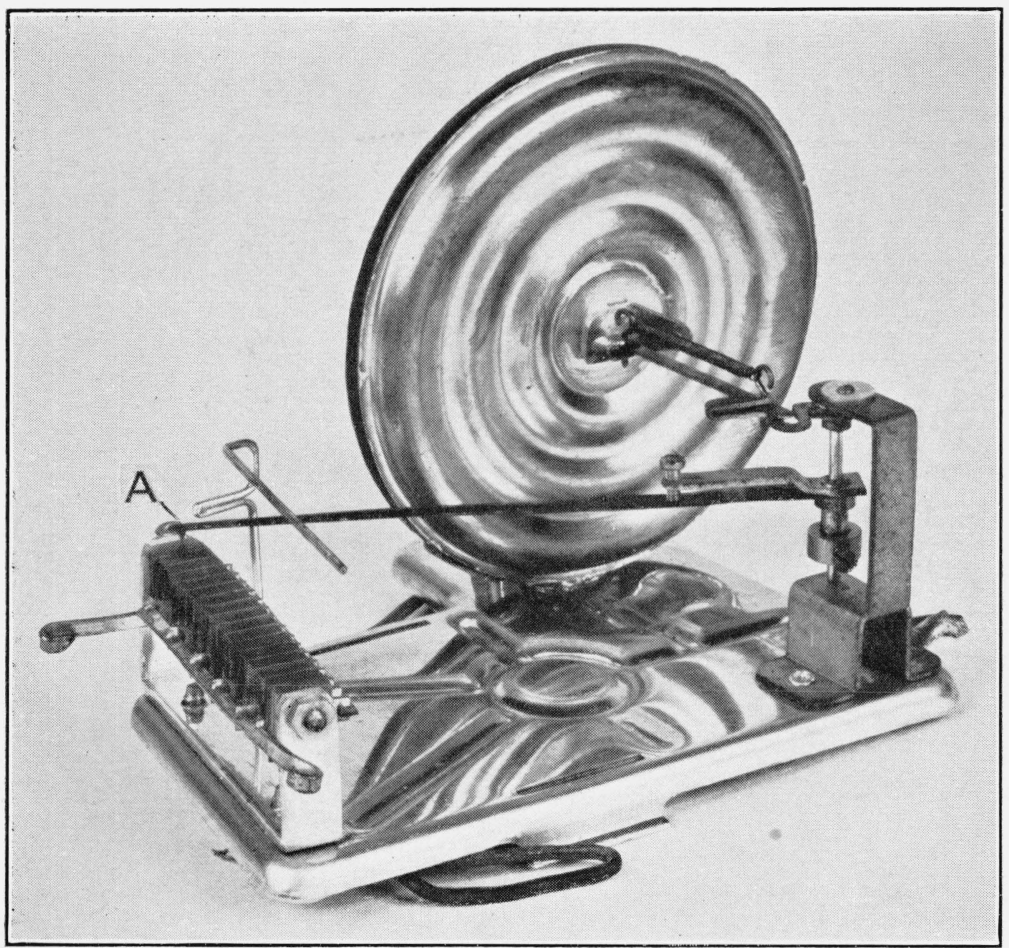

Figure 2.-New type pressure element installed in Diamond-Hinman-Dunmore radio sonde.

$A$ is the contact arm. 